Stoa

Vol. 2, No. 4, 2011, pp.55-78

ISSN. 2007-1868

\title{
EL MITO DEL CAOS PRIMIGENIO YSU VÍNCULO CON LAS COSMOGONÍAS FILOSÓFICAS DE TALES YANAXIMANDRO DE MILETO
}

\author{
Diana Toledo TOLEdo \\ Facultad de Filosofía \\ Universidad Veracruzana \\ mishturoo@hotmail.com
}

RESUMEN: En sus orígenes, la filosofía fue un intento racional de entender la naturaleza a partir de un principio en el cual se desprende, unifica y fundamenta al que los presocráticos llamaron arjé. Este texto sostiene que los modelos de cosmogonía filosófica de los milesios fueron una extensión racionalizada de los mitos cosmogónicos de Grecia arcaica, las cuales, a su vez, son reformulaciones de cosmogonías de civilizaciones antiguas como Egipto y Babilonia, que afirmaron que originariamente existió un caos primordial que se identifica con la materia primigenia de los filósofos de Mileto. PALABRAS CLAVE: Caos, Arjé, cosmogonía, indeterminación de la materia.

SUMMARY:In its origins, Philosophy was a rational intent to understand nature following a principle, from which it detaches, unifies and supports that Pre-Socratic philosophers called arjé. This text argues that the models of philosophic cosmogony of the Miletians was a rationalized extension of archaic Greek cosmogonic myths, which, in turn, are reformulations of ancient civilization cosmogonies like Egypt and Babylon, who confirmed that a primordial chaos originally existed, and it can be identified with the Miletian primordial matter.

KEY WORDS: Chaos, Arjé, cosmogony, mass indetermination.

\section{Introducción}

Cuando se habla del grandioso milagro griego lo primero que viene a nuestra mente es la apertura hacia la racionalidad científica inaugurada por los primeros filósofos jonios centrados en la comprensión de la fisis. Esta primera racionalidad científica aparentemente puede mostrarnos, en primer momento, sólo una cara de la pura razón desembarazada de especulaciones religiosas. 
Sin embargo, algunos helenistas contemporáneos han argumentado con éxito que en el origen del pensamiento filosófico griego todavía existieron notables huellas del mito, proponiendo así la idea de que la filosofía fue en principio el mito racionalizado. Lo que a continuación trataré de argumentar es que las cosmogonías filosóficas de los milesios Tales y Anaximandro fueron una extensión racionalizada de los mitos del origen del mundo. Las cosmogonías de civilizaciones como Babilonia y Egipto influyeron considerablemente en el pensamiento cosmogónico de Homero, Hesíodo y poetas órficos a los que me remito para desarrollar la idea de ver estos mitos originarios como un antecedente de la cosmogonía de los milesios. Todas estas cosmogonías arcaicas tienen un rasgo en común: en el principio era el caos.

\section{Cosmogonías no griegas: Egipto y Mesopotamia}

Sin lugar a dudas Mesopotamia y Egipto fueron la base de la cultura occidental, de éstas se desprenden los avances intelectuales como la geometría y las matemáticas que dieron origen al pensamiento filosófico de los griegos y que fue creciendo prodigiosamente por todo occidente hasta nuestros días. Sin embargo los avances científicos de estos pueblos prefilosóficos estaban fuertemente enraizados en las creencias religiosas lo que las hace despojarse del quehacer de la ciencia, entendida ésta como producto del puro entendimiento que prescinde de explicaciones divinas. Los mitos de estos pueblos trascendieron sus límites geográficos para luego servir de modelo de la cosmogonía mítica de los griegos (gracias al comercio y el intercambio de ideas culturales).

En los mitos originarios de Mesopotamia y Egipto el rasgo distintivo es que en el origen del mundo existió una masa indiferenciada acuática. Los Vedas también poseen esta misma creencia. La idea central de situar en el origen cósmico al agua tiene que ver con el hecho de que estos pueblos antiguos dependieron social y económicamente de la agricultura, por este motivo se establecieron a las orillas de los ríos pues éstos fueron elementos insoslayables para el desarrollo agrícola. Para estos pueblos las aguas son los cimientos del mundo entero: "Principio de lo indiferencial y de lo virtual, fundamento de toda manifestación cósmica, receptáculo de todos los gérmenes, las aguas simbolizan la sustancia primordial de la que nacen todas las formas y a la que vuelven, por regresión o por cataclismo" (Eliade 2007, p. 178). 
Para el caso de Mesopotamia, que prosperó a las orillas del Tigris y el Eúfrates, tenemos información de sus ideas cosmológicas en el Enuma Elish, poema que cuenta la batalla entre Marduk y Tiamat y que cada año en Babilonia se recitaba en honor a Marduk, dios quien impone el orden y la justicia en el mundo. Esto también quiere decir, que aunque el orden ya estaba impuesto, las potencias caóticas siguen representando una amenaza para el cosmos.

Para los mesopotamios, en el origen -todavía antes de las parejas sucesivas- existió una divinidad aislada, única e inmensa que por sí misma, sin ayuda de un contrario, había engendrado a la primera pareja, inaugurando así, una serie de dioses que conformarán el cosmos. Esta primera divinidad se creía que era materia caótica ( $\sin$ forma), acuosa y marina. La materia increada fue concebida como un gran organismo vivo al cual se le llamaba Nammu, una diosa madre que generó el universo. Más tarde, este catálogo de figuras míticas que se remontó hasta los comienzos del mundo, fue contado en el famoso Poema de la Creación en que Nammu se mostró ya como dos enormes masas de agua divina; Tiamat que representaba el "Agua salada" primordial y bisexuada, y que es parecida a Nammu. Tiamat posee una mayor importancia que Apsû, la segunda gran masa líquida que representaba el mar de "Agua dulce".. La primera generación de dioses poseían aún rasgos de aquellas divinidades informes primigenias. De Apsû y Tiamat surgieron Ansar (en sumerio "Cielo universal".) y Kisâr ("Tierra Universal"); estas dos divinidades representaron la totalidad del cielo y la tierra. De la pareja anterior nació Anu, quien procreó a Ea, y éste, poco después, con su mujer Damgalnunna, trajo al mundo a Marduk.

Después de la instauración del orden por Marduk, el residuo de las aguas primordiales de Tiamat que se mantenían siempre en la parte más inferior del cosmos, fue identificado con el lugar donde los muertos habitaban. A partir del triunfo de Marduk sobre Tiamat, el dios primordial que representa el caos cósmico, los espacios del universo se diferencian y determinan, haciéndose el cielo y la tierra. La función del acto de recitar el poema cada año tiene que ver con el mantenimiento del orden del cosmos: Entre los babilonios, durante el ceremonial de año nuevo, akîtu (que dura doce días), se recitaba varias veces en el templo de Marduk el poema llamado de la creación, Enuma Elish: era una manera de reactualizar por la magia oral y por los ritos que la acompañan la 
lucha entre Marduk y el monstruo marino Tiamat, lucha que había sucedido in illo tempore y que, por la victoria final del dios, había puesto fin al caos.

Cornford en su estudio Principium Sapientiae sostuvo que la batalla de Marduk contra Tiamat que se narra en el Poema de la Creación babilónica es compatible con lo que se narra en La Teogonía de Hesíodo al respecto de la sublevación de Zeus al trono del cosmos. Zeus es la versión griega de Marduk en tanto que los dos imponen un reino de justicia y liberan al mundo de las potencias del caos, Tiamat y Cronos, respectivamente.

Egipto es otra de las antiguas civilizaciones que formaron parte de los grandes eslabones del pensamiento griego y, por lo tanto, del pensamiento occidental. Gran parte de los conocimientos astronómicos, matemáticos y geométricos que practicaron los griegos fueron de origen egipcio. Pero incluso por muy avanzadas que hayan sido sus especulaciones, su pensamiento no llega a ser, ciertamente, conocimiento "puro". a diferencia del pensamiento filosófico griego. La ciencia egipcia se hallaba fuertemente adherida a las prácticas agrarias, económicas y al quehacer sacerdotal del pueblo egipcio: "El propio testimonio de los griegos, los filósofos y lo sabios del mundo helénico - desde Orfeo hasta Platón- recurrieron a los sacerdotes egipcios en casi todos los dominios del conocimiento: geometría, astronomía, meteorología, medicina, etc. La deuda de los griegos respecto a Egipto, notablemente inflada por Herodoto, fue desmesuradamente aumentada por los neoplatónicos orientalizantes que se consagraron a reencontrar sus propias especulaciones en los mitos egipcios recurriendo a un discutible método alegórico" (Parain 1999, p. 7).

La vida de Egipto siempre permaneció en función del Nilo. Para ellos, ni la agricultura ni la ganadería hubieran sido posibles sin las inundaciones. A los egipcios les pareció totalmente contrastante la "tierra negra". que dejaba la inundación anual y la "tierra roja". que representaba el desierto inerte que los rodeaba. El Nilo fue la base vital para la supervivencia de la cultura, es por eso que su pensamiento cosmogónico tuvo como origen también un caos acuático. Es importante señalar que se le da a las aguas del Nilo una connotación caótica (por el mismo problema de la inundación anual); por un tiempo parecía una catástrofe natural, y después mantenía el orden el resto del año, además, proveía de nutrientes para una cosecha satisfactoria. 
Esta cultura tuvo la visión de un mundo amenazado por el caos por los problemas políticos que Egipto sufrió. Durante un tiempo fue gobernado por extranjeros y geográficamente la civilización se situó en un espacio en el que muchas culturas se encontraron en la periferia. Egipto siempre fue un lugar conquistable y amenazable por éstas. Era evidente que, por poderoso que pareciera Egipto, lo cierto es que nunca fue absolutamente seguro, lo cual determinó sin duda su visión del cosmos.

El mundo para los egipcios se engendró de una masa acuática primigenia indiferenciada e informe. Existieron varias versiones acerca del origen del mundo pero todas ellas coincidieron en que en principio sólo existió el caos; el cosmos no es la obra de un dios que haya existido eternamente. El caos acuático es inexplicable para ellos: es la negación del mundo presente, no se asemeja a nada de él; es el estado previo a la formación del cosmos: "antes de que existiera el cielo, antes de que existiera la tierra, antes de que existieran los hombres, antes de que nacieran los dioses, antes de que existiera la muerte". (Cohn 1995, p. 18). El caos era una sustancia material que los egipcios denominaron Nun, un océano sin límites: "La oscuridad reinaba en la superficie de las profundidades, porque el sol aún no existía. Pero en el interior de aquel abismo oscuro y acuoso yacía en estado latente la sustancia primitiva con la cual se formaría el mundo. Sumergido también en algún lugar del abismo estaba el demiurgo que se encargaría de darle forma. Pero también el demiurgo existía sólo en potencia, no era aún consciente de sí mismo ni de la tarea que debería llevar a cabo". (Ibídem, p. 18).

Lo primero que emergió de las aguas caóticas fue un pequeño islote, lo cual refleja sin duda la repetición anual de la cosmogonía, es decir, la inundación del Nilo: el espectáculo de una tierra sumergida que después resurgía con una tierra fresca y provista de fertilidad.

Nun, la divinidad originaria, no tuvo fuerza activa para dar forma al mundo, de esto se encargó el demiurgo: el caos original era un estado de indiferenciación y desorganización material unitaria y el demiurgo se encargó de definirlo, diferenciarlo y ordenarlo. Mientras que el caos era ilimitado, en el mundo ordenado existían límites que empezaron a surgir con el demiurgo: él arrojó la luz y gracias a ésta todo puede existir por separado; él transformó lo unitario en múltiple. Para los antiguos egipcios el caos primario contenía una serie 
de monstruos que poblaban el mundo subterráneo, concebido éste también como un abismo insondable.

Un monstruo del inframundo que se manifestaba como una encarnación del caos era Apofis. Éste era de aspecto informe ya que era asexuado; no poseía órganos sensitivos y su único rasgo era que sólo podía emitir gritos. Apofis sólo actuaba en la oscuridad y estaba presente en ella, sobre todo en los momentos cruciales como la caída y fin de la noche, un eclipse, etc.

El caos tiene que ver con la oscuridad, con una disolución de formas en el que no existen miembros ni, por tanto, papeles específicos; ahí todo se encuentra en un estado de latencia en el que todo puede ser posible llevando consigo un alto grado de incertidumbre.

Estas cosmogonías acuáticas no se desligan en absoluto de la práctica social de los pueblos, sino que están estrechamente ligados: el orden del mundo se comprende a partir del orden de la ciudad. La batalla anual con las potencias caóticas primordiales tenían que garantizar la estabilidad y el orden del pueblo; el medio ambiente tendía a una regresión cíclica al estado caótico primigenio por lo que los ritos constituyeron una forma de consagrarse al mundo natural para que el orden y la prosperidad emergieran de nuevo. Orden, tuvo que ver con que cada miembro, sea de la naturaleza o de la cuidad, desempenara un papel específico, cumpliera su función y mantuviera la armonía con los demás miembros. Sin embargo, el caos primario o Nun nunca había dejado de existir: formaba parte todavía del universo, rodeaba la tierra y acontecía en el mundo subterráneo. Nun representó para la cultura egipcia un aspecto ambivalente; a la vez que se presentaba como una amenaza para la cultura (política y cosmológicamente), tenía una función positiva, pues sin el resurgimiento del caos como inundación anual, la vida orgánica o la agricultura hubieran sido nulas.

\section{El mito del caos originario en Grecia antigua}

En los mitos cosmogónicos de Grecia antigua también encontramos que en principio existió una materia indiferenciada al que Hesíodo llamó Caos. Esto se debió que gracias al intercambio comercial y cultural que hubo entre el pueblo helénico y otros pueblos indoeuropeos. La influencia de Oriente en Grecia es indiscutible y esto se reflejó notablemente en su percepción del 
cosmos y la naturaleza. Por ejemplo, como antes mencioné, Cornford muestra que La Teogoníade Hesíodo posee una gran similitud con el poema cosmogónico babilonio Enuma Elish, que incluso las etapas principales de la narración son casi idénticas que van desde que en el origen existió una masa de materia indeterminada hasta la sublevación de la justicia del dios que mantiene el orden del mundo, sea en un caso Zeus y el otro Marduk.

Lo que haré a continuación será abordar el pensamiento cosmogónico en los mitos de la Grecia antigua tomando en cuenta el elemento que propusieron algunos poetas como punto de origen común de la totalidad del cosmos. Haré notar que todos estos elementos propuestos parecen identificarse con el caos acuático primigenio del que hablaron las cosmogonías orientales expuestas anteriormente.

Debo decir, que a mi parecer, Hesíodo es quien unificó todas las características en un mismo elemento primordial: El Caos. Aunque varias de las cosmogonías alternas a la hesiódica, que se expondrán a continuación, son incluso contemporáneas o posteriores a la mencionada, el Caos hesiódico es el que se muestra con más exactitud explicativa para la comprensión del origen del mundo porque es lo que conjunta las características de indeterminación, oscuridad, inasibilidad racional e inestabilidad material del estado originario. Esto servirá como punto de partida para comprender la cosmología de la escuela de Mileto que será expuesta en el capítulo siguiente y poder trazar las líneas de continuidad entre los mitos cosmogónicos y la cosmogonía filosófica, y comprender el andamiaje mágico-religioso que tuvieron los elementos primigenios propuestos por Tales y Anaximandro.

Homero, quien fue uno de los grandes parangones de la cultura griega propuso que Océanos estaba en el principio de todas las cosas; es el padre absoluto de todos los dioses: "Algunos dicen que los dioses y todas las criaturas vivas se originaron en la corriente de Océano, que envuelve al mundo, y que Tetis fue la madre de todos sus hijos". (Homero, Il, XVI, 201). Océano así como fuente teogónica es fuente de todas las aguas: "A éste ni el poderoso Aqueloo le iguala, ni la gran fuerza de Océano, de profunda corriente, de quien, en verdad, todos los ríos, todo mar, las fuentes todas y los profundos pozos dimanan". (Homero, Il, XXI, 194). Si él es fuente de todas las aguas se sigue que de él brotan tanto el agua salada como el agua dulce, al igual 
que en el poema mesopotamio donde Tiamat es fuente de todas las aguas: "Las aisladas referencias de Homero a Océano como origen de todas las cosas parecen concluir que esta imagen es una probable alusión a ideas mitológicas de origen no griego. En las versiones babilonias y en algunas de las egipcias se consideraba que la tierra estaba en estado de desecación o de emergencia en medio de las aguas primigenias". (Kirk y Raven 1987, p. 33).

Notablemente Homero tuvo influencia de cosmogonías orientales al decir que lo primero que aconteció fue el dios que representa la gran masa acuática que rodea la tierra: Océano. Esto es un posible indicio de que de ello también se derivara más tarde la cosmogonía filosófica de Tales de Mileto. La idea cosmológica del agua conlleva a una serie de elementos míticos y mágicoreligiosos que llenan a este elemento una fuerte carga simbólica. "Conforme al simbolismo general de las aguas, dulces o saladas, el océano simboliza el conjunto de todas las posibilidades contenidas en un plano existencia. Del aspecto se puede deducir el carácter positivo (germinal) o negativo (destructor) de tales posibilidades. Por ello, el océano expresa una situación ambivalente; como creador de los monstruos es la perfecta morada abisal, la fuente caótica de donde aún emergen lo inferior(...)Por esta razón los monstruos marinos exponen una situación cósmica de estrato más bajo que la de los monstruos terrestres; por esta causa las sirenas y tritones aluden a una infraanimalidad". (Cirlot 1997, p. 344).

En el océano primigenio el mundo está disuelto y en potencia de ser "cosmos".; es el germen de toda manifestación cósmica y al mismo tiempo muestra un aspecto ambivalente de creación y destrucción porque de él se deriva todo, cuando el mundo llega a conformarse tal como lo vemos de ordenado, no deja de verse a Océano como una amenaza, divinidad temible y capaz de destruir. Su relación con el inframundo muestra ese aspecto que el mundo debe temer. En Homero vemos esta relación en La Odisea en el viaje de Ulises al inframundo: el héroe va en busca de Tiresias al Hades y para llegar ahí es necesario transitar en Océano, en el Hades también encuentra a su madre quien le dice: "¿Hijo mío, cómo has bajado a la nebulosa oscuridad si estás vivo? Les es difícil a los vivos contemplar esto, pues hay en medio grandes ríos y temibles corrientes, y, antes que nada, Océano, al que no es posible atravesar a pie si no se tiene una fabricada nave". (Homero Od., canto XI). 
El vínculo con la materia divina primigenia con el inframundo, lugar donde habitan los muertos y los monstruos es muy común: los egipcios y babilonios relacionaban a Nun y a Tiamat con la parte inferior del cosmos, zona oscura y fría, residuos de lo primero que existió. Homero vincula también al infierno con Océano quien sirve de tránsito hacia él y parece ser que incluso es una extensión del mismo. La mención de la laguna de Estigia, donde fue sumergido Aquiles y de dónde obtuvo sus dotes de guerrero, por ejemplo, da un punto a favor a la idea de que en el infierno yace aún el agua sagrada.

Más claro es el caso de la relación del inframundo con lo primigenio en las cosmogonías órficas que proponen la Noche, el Tártaro y el Aer como los dioses que estuvieron el en principio y que dieron lugar más tarde al cosmos: "En los versos atribuidos a Epiménides todas las cosas se componen del Aire y de la Noche; como también Homero declaraba que Océano engendra de Tetis a los dioses (Filodemo, De pietate 47a [DK 3 B 5])" (Kirk y Raven, 1987, p.41). Todos estos dioses primordiales son profundamente relacionados al Hades. La importancia de cosmológica de la Noche como divinidad primigenia radica en su carácter de oscuridad y precariedad: "La Noche es el primer principio de la cosmogonía órfica recogida por Eudemo: no es mera ausencia de luz, sino el aire oscuro, frío y húmedo. Aristóteles compara a la Noche de la que los teólogos generan el mundo con la "reunión de todas las cosas". de los filósofos físicos y con el Caos de Hesíodo (Aristóteles Met. 1071 b 26)”. (Cornford 1998, p. 229).

Lo oscuro en el origen significa la matriz de todo lo posible y lo existente; en lo negro no existe determinación alguna, todo está sumergido en un estado de unificación total. En la Noche nada se distingue, por lo que la alusión a esta divinidad en los mitos, puede ser también simbólica. Lo posterior es la luz, la distinción y la claridad, "identificada con la materia, con lo maternal y germinal; es anterior a la diferenciación de lo concreto. El dualismo luz-tinieblas no aparece como formulación de un simbolismo moral hasta que la oscuridad primordial se ha dividido en luminosidad y sombras. Así, el concepto puro de dicha oscuridad no se identifica tradicionalmente con lo tenebroso; contrariamente, sí corresponde al caos primigenio”. (Cirlot 1998, p. 350).

Todas estas ideas cosmológicas antes expuestas indican que finalmente a lo que se quiera llegar es a establecer que en el principio lo que existió es una 
materia indiferenciada divina. Todo esto se conjugó en La Teogonía de Hesíodo para quien esta masa indeterminada originaria se llamó Caos.

\subsection{El caos hesiódico como síntesis de las ideas cosmogónicas}

Hesíodo vivió aproximadamente en el siglo VII a. d. C., fue el autor de $L a$ Teogonía y Los Trabajos y Los Días, dos de los textos más significativos para la cultura griega; el primero se centra en la narración del origen de los dioses, remontándose incluso hasta el inicio de los tiempos, para desembocar a los tiempos del dominio de Zeus, quien impone el reino de justicia y orden en el cosmos.

Hesíodo se remontó hasta los orígenes del mundo, de manera que incluso se hace notar un orden material de la conformación de él ya que lo primero que existió fue el hiato originario del que surgen potencias cósmicas bien definidas como Gea (la tierra) y Uranos (el cielo), para luego, progresivamente, dar origen a los dioses de forma antropomórfica cuyo culmen es la generación de los olímpicos. Los dioses preolímpicos no precisamente fueron dotados de forma y actitud humana, más bien representaron potencias de la naturaleza que deidades morales como lo son los dioses olímpicos. "Lo vivo y lo animado no tiene que ser en estricto sentido 'persona'. Es el caso de las deidades olímpicas. Sin embargo cada una de ellas es un individuo viviente, ideal y materialmente. Por cierto que esto ha sido impugnado algunas veces, por ejemplo por F. M. Cornford quien ha postulado la separación entre individuo y deidad en los dioses preolímpicos y prehoméricos. En las deidades preolímpicas se ve más bien especies, por lo cual, según su opinión, la filosofía de los presocráticos, con su afán por las generalizaciones lógicas abstractas, pudo vincularse con ellas más fácilmente". (Hübner 1993, p. 108).

Si bien la obra de Hesíodo no fue considerada como filosófica, su poesía hizo una gran contribución en cuanto a la preocupación de acercarse a la verdad y al principio del mundo. El Principio y la Verdad son las dos cuestiones fundamentales por las se originó la filosofía. Hesíodo intentó llegar a ellas cuando las musas le cantan: "Sabemos decir muchas mentiras con apariencia de verdades; y sabemos, cuando queremos, proclamar la Verdad". (Hesíodo, Teog. 28). Esta verdad consiste en revelarle el origen del cosmos, ese origen del cual surgió todo y que repercute en nuestro presente: "Las musas cantan, 
en efecto, comenzando por el principio - $\varepsilon \xi$ apxńs: aparición del mundo, la génesis de los dioses, el nacimiento de la humanidad. El pasado de esta forma desvelado es mucho más importante que el antecedente del presente: es la fuente del presente. Remontándose hasta él, la rememoración busca, no el situar los acontecimientos dentro de un marco temporal, sino alcanzar en fondo mismo del ser, descubrir el original, la realidad primordial de la que ha salido el cosmos y que permite comprender el devenir en su conjunto" (Vernant 2001, p. 95).

Hesíodo cantó desde el principio de todos los tiempos porque esto revela lo más verdadero real. La Teogonía es la narración del proceso de sublevación del gobierno justo de Zeus que hace posible un mundo armonioso. Pero antes de esto es necesario saber qué sucedió antes de esto para poder comprender la totalidad y las leyes inquebrantables del cosmos.

Las cosmogonías no griegas que mencioné en el apartado anterior tuvieron la intención de entender el orden del cosmos; lo mismo sucede con Hesíodo: lo que le interesó al poeta es saber cómo la armonía ha podido emerger de una situación caótica. Para Hesíodo, el principio debió ser lo más confuso e indeterminado, de lo cual ha de surgir todo lo determinado. El poeta buscó un principio que está más allá de lo visible, una divinidad que está más allá de las divinidades antropomórficas e incluso más allá de las asociadas con las potencias naturales, como Gea y Urano: "En primer lugar existió el Caos. Después Gea la de amplio pecho, sede siempre segura de todos los Inmortales que habitan la nevada cumbre del Olimpo. [En el fondo de la tierra de anchos caminos existió en tenebrosos Tártaro] (Hesíodo, Teog., 117).

Gea, junto con Urano que "la cubre en todas sus proporciones". conforman el cosmos y es hábitat seguro para dioses y humanos, lo que permanece fuera de él es Caos que engendró en su seno a Érebos y la Negra Noche. Estas dos divinidades comparten con Caos la oscuridad: "La línea genealógica -que comienza en la serie anterior con el Caos y Érebo para terminar en las Hespérides- está determinada por cierta analogía o similitud entre sus miembros, pues a todos se les adhiere algo oscuro y nocturno. Por lo tanto, se trata de una especie de desdoblamiento de variantes distintas de algo homogéneo en su forma" (Hübner 1993, p. 109). 
Érebo, representó tradicionalmente para la mitología griega, el lugar de los muertos. Estuvo estrechamente relacionado con Tártaro, y, de hecho, la distinción de estas divinidades no parece ser muy clara. Así, podemos ver una fuerte relación entre Caos y la zona en donde tradicionalmente habitaban los muertos. Mircea Eliade hace patente dicha relación: "Lo que caracteriza a las sociedades tradicionales es la oposición que tácitamente establecen entre un territorio habitado y el espacio desconocido e indeterminado que los circunda: el primero es el "mundo"., el cosmos; el resto ya no es un cosmos, sino una especie de "otro mundo". un espacio extraño, caótico, poblado de larvas, de demonios, de extranjeros (asimilados por los demás, a demonios o fantasmas) (Eliade 1998, p. 27).

Las referencias al mundo de los muertos como lugar desconocido, el "otro mundo". y que los humanos tienen cierta imposibilidad de acceder, son comunes en los mitos antiguos. Los héroes de la mitología tuvieron en algún momento de su vida acceso a este lugar; tales son los ejemplos de Ulises y Orfeo, incluso, remontándose hasta la mitología babilónica, el caso de Gilgamesh. En la tradición griega, Ulises descendió al Hades para que el sabio Tiresias le indicara la sabiduría para llegar a su destino, Ítaca; Orfeo fue con la intención de traer de nuevo Eurídice al mundo de los vivos, pero aunque no logró su cometido, posteriormente es acusado por Zeus por develar a los mortales los secretos divinos (Graves 2007, p. 148).

Existen varias interpretaciones en cuanto al espacio que ocupa Caos en el universo pero dos son las más destacadas: una, tomada sobre todo de Aristófanes en Las Aves que propone que Caos está situado entre el cielo y la tierra, es el resquicio existe entre ellos, es decir "un espacio intermedio donde vuelan las aves". (Martínez Nieto 2000, p. 65); la segunda interpretación nos indica que es más pertinente ubicar a Caos en el espacio del inframundo (teniendo en cuenta la relación existente entre Caos y Tártaro) puesto que el mismo Hesíodo nos lo hizo explícito: "Allí de la tierra sombría, del tenebroso Tártaro, del ponto estéril y del cielo estrellado están alineados los manantiales y términos hórridos y pútridos de todos, y hasta los dioses los maldicen. Enorme abismo: no se alcanzaría su fondo ni en todo un año completo, si antes fuera posible franquear sus puertas; sino que aquí y por allá te arrastraría huracán 
ante huracán terrible. Horrendo, incluso para los dioses inmortales, este prodigio" (Hesíodo, Teog. 136).

El inframundo o Tártaro tiene una compatibilidad con el significado de Caos. Hesíodo parece que lo toma no sólo como una extensión sino incluso como un sinónimo (como lo vemos en la cita anterior de La Teogonía). Muchos estudiosos comparten esta idea, por ejemplo, Cornelius Castoriadis en uno de los seminarios dedicado a la cosmogonía hesiódica, compilados en el libro Lo que hace a Grecia, afirmó que Caos se determina en Tártaro. Los hermanos Böhme también declararon: "A partir de él (Caos) surge la tierra (Gea), y en ésta, "debajo"., como otro Caos, el Tártaro, yacente en lo sombrío" (Böhme 1998, p. 39).

$\mathrm{Si}$ vinculamos al Tártaro con Caos y lugar de los muertos, entonces es probable que Hesíodo haya creído que Zeus, cuando vence a los Titanes, los hace retornar al estado primordial, fuente de la vida y del cosmos, (suceso descrito en $L a$ Titanomaquia) por castigar su crueldad e injusticia en contra de Uranos cuyo escenario en La Teogonía se narra en El Mito de la Castración de Urano. Hesíodo sugirió que el gobierno del cosmos de los Titanes no es un gobierno justo, sino que permanece aún en los dominios de la hybris.

El orden cósmico en La Teogonía hesiódica depende de la lucha de Zeus en contra de los Titanes, al igual que en la cosmogonía babilónica el cosmos depende de la lucha entre Marduk contra Tiamat: Marduk es el dios que instaura el equilibrio y el orden del mundo por lo que El Poema de la Creación es un himno a Marduk, análogo a La Teogonía como un himno a Zeus. Estos dos dioses, uno de tradición mesopotámica y el otro de tradición griega, surgieron en la tercera generación de los dioses.

En La Teogonía, se repitió casi el mismo proceso por el que se instaura el poder de Marduk, para la sublevación del poder de Zeus; Ea, padre de Marduk, es análogo a Cronos, y aunque Marduk no luchó precisamente en contra de Ea sino con Tiamat, la batalla en nombre del orden cósmico muy parecida a la versión hesiódica. F. M. Cornford en Principium Sapientiae afirmó con rigor que Hesíodo tomó como modelo cosmogónico el Enuma Elish babilonio. Las compatibilidades existentes entre la visión de un estadio caótico de los orígenes y la separación del cielo y la tierra a partir de éste, la lucha por la autonomía, el orden y la equidad no sólo cósmica sino también en niveles referentes a la 
vida social y política de los pueblos, son puntos de referencia para hacer visible la influencia del pensamiento de Oriente Próximo en la conformación del pensamiento griego.

El retorno a lo primigenio que planteó Hesíodo en el momento de la instauración de la justicia de Zeus cuando éste devuelve al Tártaro a los Titanes, tiene que ver con la idea de garantizar el orden y la armonía del mundo. Todo lo que en algún momento tuvo un exceso de poder y desmesura (hybris) tiene que retornar al origen en donde esto no acontece. El problema del principio de individuación radica en que existe cierto rango de poder que posibilita esta sublevación. De manera análoga podemos interpretar que la vida es así: surge ante la lucha y el triunfo frente a algo que se le opone. Pero tarde o temprano ese exceso de poder se termina cuando la ley inquebrantable del cosmos hace pagar esa injusticia devolviéndonos a la matriz originaria y, con esto, abrir paso a nuevas formas de vida: "La muerte no muestra ser ya sino un cambio provisional en la manera de ser. El invierno no es nunca definitivo, pues va seguido de una regeneración total de la naturaleza, de una manifestación de formas nuevas e infinitas de la vida; nada muere realmente, todo se reintegra en la materia primordial y reposa en espera de una nueva primavera. Cualquier valorización del mundo fundada por el ritmo, sobre el eterno retorno, no puede evitar los momentos dramáticos; vivir ritualmente los ritmos cósmicos significa en primer lugar vivir en tensiones múltiples contradictorias" (Eliade 2007, p. 300).

La justicia de Zeus parece ser, en La Teogonía, un puente entre el cosmos (formado por Gea y Urano) con lo originario (puesto que se retorna a este estado). La noción de justicia en Hesíodo no sólo funciona en el mundo de los hombres y de los dioses, sino también en el mundo físico: al ser Zeus rey de dioses significa que lo rige absolutamente todo: el macrocosmos y el microcosmos. Zeus fue, en Hesíodo, el punto unificador de La Teogonía (el mundo de los dioses) y Los Trabajos y Los Días (mundo humano).

\section{La filosofía milesia y el problema del caos mítico}

Los pensadores milesios abandonaron las explicaciones mitológicas y sobrenaturales del origen y el orden del mundo; ellos impusieron una nueva forma de explicación y vía de acceso hacia el orden y la comprensión del cosmos: el 
puro razonamiento. Con ello trataron de establecer, ya no un saber mostrativo como en los mitos, sino un saber demostrativo. Cornford afirmó que los milesios tomaron como dogmas o principios indubitables lo que los grandes poetas griegos dijeron a través de sus mitos: "Los milesios operan sobre ciertas suposiciones tácitas que nunca se les ocurre justificar porque están tomadas de la cosmogonía poética”. (Cornford 1998, p. 225). El filósofo se instaló en el reino de la totalidad de lo real, de lo oculto y lo divino y explicó racionalmente cómo esta Verdad se despliega en la physis.

La pugna que la filosofía tuvo con la poesía consistió en que la primera sometió a crítica la segunda y que, por tanto, esta última no satisfizo un quehacer racional del mundo al que todos los hombres incluso pueden ser capaces de acceder. La filosofía griega fue un arduo intento de desembarazase de las visiones enigmáticas y divinas acerca del universo, pero también es importante señalar que, por ejemplo, los filósofos milesios hacen de sus elementos primordiales un elemento que en el fondo no se divorcia del carácter divino: sus principios cosmológicos tienen la característica de algo que rebasa todas las formas determinadas del mundo tangible, algo que incluso está fuera de él pero que es y seguirá siendo por la eternidad, el elemento base y fundacional del cosmos.

Los naturalistas milesios Tales y Anaximandro, proponen como sustancias primordiales elementos que parecen tener similitud con las divinidades primigenias de las cosmogonías míticas antes expuestas puesto que todas tienen las características de ser materia indeterminada y sin forma.

\subsection{El agua primordial de Tales de Mileto}

Tales de Mileto, el primer filósofo de la historia, vivió en el siglo VI a. de C. Fue comerciante y esta labor le permitió tener contacto sobre todo con la civilización egipcia. El papel de Tales en la labor mercantil fue de gran importancia puesto que esta actividad -de origen fenicio al igual que él mismo- repercutió profundamente en la formulación de su sistema cosmológico al haberse familiarizado más con el ambiente marítimo y permitirle los continuos viajes, sobretodo a Egipto, de donde tomó conocimientos matemáticos y geométricos. "Grecia no es un país en donde la tierra se muestre tan fértil como en Babilonia y Egipto, por eso desarrollaron primordialmente, aunque 
no desde el principio, el comercio y la navegación. De hecho esto lo heredan más bien de la tradición fenicia, quienes desde luego desempeñaron una fuerte influencia sobre todo para el pueblo jonio" (Grimberg, Svanström 1967, p. $78)$.

El conocimiento de la cosmología de Tales de Mileto se resume en el siguiente párrafo de La Metafísica de Aristóteles: (Aristóteles, Metafísica, A 3, 983 b 6). La mayoría de los primeros filósofos creyeron tan sólo principios aquellos que se dan bajo la forma de la materia; pues afirman que el elemento y principio primero de todas las cosas es aquel que a partir del cual todas las cosas existen y llegan por primera vez al ser y en que terminan por convertirse en su corrupción, subsistiendo la sustancia pero cambiando en sus accidentes; porque tal naturaleza se conserva siempre(...), pues es necesario que haya alguna sustancia natural, una o múltiple, de la que nazcan las demás, mientras ésta se conserva. Respecto al número y la forma de tal principio no todos están de acuerdo, sino que Tales, el iniciador de tal tipo de filosofía, dice que es al agua (por lo que manifestó que también la tierra está sobre el agua), tomando, tal vez, dicha suposición de la observación de que el alimento de todas las cosas es húmedo y que el calor mismo surge de éste y vive de éste (el principio de todas las cosas es aquello de donde nacen): de aquí dedujo su suposición y del hecho de que la semilla de todas las cosas tiene una naturaleza húmeda; y el agua es el principio natural de todas la cosas húmedas (Trad. Kirk y Raven, 1987, p. 127).

Este elemento propuesto por Tales de Mileto como principio generador del mundo debe interpretarse, no como el elemento tal cual lo conocemos en la vida diaria, sino como un elemento abstracto que es la matriz vital del cosmos. El apego de Tales con la cultura Egipcia pudo haber influido considerablemente en su cosmogonía acuática, ya que, se sabe que los egipcios concebían como elemento primigenio un caos acuático, explicado ya en el primer apartado. Quizás este elemento también se le hizo compatible para explicar su entorno físico porque Grecia está básicamente rodeada de costas.

Lo acuático puesto en los orígenes del mundo también se encontró esbozado en Homero: en La Odisea afirmó que todo proviene de Tetis y Océano. Como abordé en el capítulo anterior, Océano se muestra como la divinidad más arcaica y aparentemente disforme; es un dios que posee una imagen caó- 
tica. El viaje de Ulises (narrado en La Odisea) por el océano, nos muestra a éste como un dios bastante discorde y enigmático; al sumergirse en su seno, se muestra como tránsito al inframundo, por eso también Dioniso, en las Bacanales, se sumerge en él cuando retorna a la morada de los muertos. ${ }^{1}$ Este punto, en el cual podemos conectar a Océano con el inframundo, descansa también sobre la idea antes expuesta - en la cita de Aristóteles- en donde se informó que Tales concibió que la tierra flotaba sobre el agua y que sus raíces, por tanto, se encuentran en ella. La relación de las aguas primigenias con el inframundo también es una característica de las cosmogonías acuáticas no griegas. Por ejemplo en la tradición babilónica, Apsû representó las aguas subterráneas después de que Marduk crea el orden cósmico.

Si para Tales de Mileto el agua significó el arjé, quiere decir que en este elemento se originan y retornan los demás componentes de mundo. Esta idea se hace compatible con la creencia de la repetición del momento de la creación a través de las inundaciones del Nilo puesto que se retorna al estado caótico primordial. Además la relación de lo primordial con el inframundo sugiere que la muerte es vista como un retorno a este mismo estado originario.

El agua tiene un trasfondo mágico y simbólico muy importante para la historia de las religiones de los pueblos antiguos. Los Vedas también creían que en el principio todo era como un mar profundamente oscuro; en la India se considera a este elemento como el que circula por el mundo y por la vida en forma de lluvia, leche, sangre, savia. Se asocia al agua al elemento primordial e ilimitado que rodea la tierra: "Dentro de su aparente carencia de forma se distinguen, ya en las culturas antiguas, las "aguas superiores". de las "aguas inferiores"., las primeras corresponden a las posibilidades aun virtuales de la creación, mientras que la segundas conciernen a lo ya determinado(...) más aun, en las aguas primordiales, imagen de la protomateria, se halla también los cuerpos sólidos aun carentes de forma y rigidez" (Cirlot 1997, p. 68).

Las aguas, por su aspecto informe y profundidad también se le asocia al abismo insondable y misterioso. Los diluvios y las inundaciones nos remiten a la capacidad de destrucción que producen nuevos estados cósmicos; así, el agua

\footnotetext{
${ }^{1}$ Esta información se sustenta en unas referencias de que Dioniso es una divinidad infernal (Eduardo Cirlot). Se le aribuye una opinión a Heráclito que dice: El Hades y Dioniso, por el que se enloquecen y celebran las fiestas Leneas, son lo mismo. (Frg. 15, Clemente, Protréptico 22. Traducción de Kirk, Raven y Schofield, Los filósofos presocráticos).
} 
muestra un papel ambivalente: uno como creador y otro como destructor. "En suma, las aguas simbolizan la unión universal de las virtualidades que se hallas en la precedencia de toda forma o creación. La inmersión a las aguas significa el retorno a lo preformal, con su doble sentido de muerte y disolución, pero también de renacimiento y nueva circulación, pues la inmersión multiplica el potencial de la vida". (Ibídem, p. 69).

Con esto no es desdeñable la idea de que muchas ideas religiosas y simbólicas influyeron y acompañaron la formulación cosmogónica de Tales de Mileto, sobre todo ideas de origen oriental. Su constante relación con Oriente a través del comercio marítimo pudo haber sido el punto clave para la conformación de su filosofía.

\subsection{Anaximandro y el ápeiron}

Anaximadro de Mileto, sucesor de Tales (VI a. de C) y segundo filósofo de la historia añade el concepto de arjé para llamar al elemento primordial donde se origina y sustenta el cosmos. Al igual que Tales, intentó establecer una manera de conocer la Verdad a través de la razón sin necesidad de recurrir a dioses. El mundo, para él, es fundamentado y generado por un principio material eterno e inmutable al que llamó Ápeiron: (Simplicio Fis. 24 I3) De entre los que dicen que es uno, moviente e infinito, Anaximandro, hijo de Praxiades, un milesio, sucesor y discípulo de Tales, dijo que el principio y el elemento de las cosas era el ápeiron [infinito o indefinido] habiendo sido el primero en introducir este nombre de principio material (Trad. Kirk 1987, p. 149).

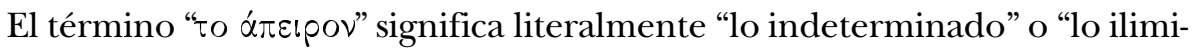
tado". Anaximandro creyó que este elemento primigenio supera los límites y los demás elementos concretos del cosmos. Mediante esto sugiere que el arjé es un cúmulo de materia indeterminada de donde surgieron los elementos componentes del mundo como el aire, el agua, la tierra y el fuego. Para él la matriz primordial y fundacional no puede ser algo como el agua -replicando la idea de Tales- sino un principio más allá de lo visible y determinado. El ápeiron es eterno, incorruptible e infinito. Es notable que el concepto del ápeiron haya sido una reformulación del pensamiento de Tales de Mileto pero con un nivel más abstracto. Sin embargo, no por esto quiere decir que esté exento 
influencia mítica, sino que Anaximandro parece haber tomado elementos de La Teogonía de Hesíodo para la configuración de su cosmología filosófica.

Debemos entender que el ápeiron es una sustancia material indeterminada e informe que dio origen a todas las formas del mundo mediante un proceso de separación, esta matriz primera tiene que ser más primitivo que cualquier otra entidad componente del cosmos como el agua o la tierra. El caos hesiódico que se describe en La Teogonía tiene la misma característica de materia informe de donde se separan dioses como Gea y Urano (los dos primeros contrarios) que son, al mismo tiempo, fuente de generación divina. Gracias a esto encontramos un primer paralelismo entre el elemento primordial filosófico y racional de Anaximandro y la sustancia mítica primaria de Hesíodo.

El proceso de separación de los contrarios en el ápeiron y el Caos hesiódico es una forma racional de explicar el devenir: el cambio, por ejemplo en las estaciones del año, cada elemento se pone en pugna con su oponente natural por lo que uno necesariamente triunfa y decae de acuerdo a cierta temporada: de esta manera, en cada estación existe sólo el predominio de un elemento. Los contrarios explican la generación de la vida; no puede existir vida sin que acontezca la conjunción de ellos (macho-hembra). La pugna natural que existe entre los opuestos es parte de la armonía del cosmos y esto se logra comprender a través de la noción de justicia (que impera la totalidad de lo real).

El siguiente fragmento muestra el orden del mundo del cosmos a partir de una noción de justicia inherente a él mismo: (Simplicio, Fis. 24, 13-25) "Ahora bien, a partir de dónde hay generación para las cosas, hacia allí también se produce la destrucción, según la necesidad; en efecto, pagan la culpa unas a otras y la reparación de la Injusticia".. El retorno a lo indeterminado significa, para Anaximadro, pagar la expiación de la injusticia que cometieron a su opuesto. Este retorno se cumple gracias al movimiento eterno y cíclico de ápeirón-injusticia-justicia; la justicia es imprescindible en la armonía del movimiento cósmico. Cada vez que un elemento se segrega de su matriz comete un acto de injusticia por su status de individualidad en el mundo y pagar esta injusticia significa retornar al mismo estado de donde emergió. El retorno al ápeiron parece significar un retorno a una igualdad ontológica donde se carece de individualidad. 
En el ápeiron no existe distinción alguna, es una masa informe que contiene en sí todas las posibilidades disueltas en una unidad eterna y en continuo proceso de generación de elementos y formas de vida, quedando al mismo tiempo una reserva para dar lugar posteriormente otras formas de manifestación cósmica mientras otras retornan al estado primigenio. "Anaximandro delata los moldes del pensamiento hesiódico cuando sostiene que estos innumerables mundos-dioses salen genealógicamente de esta misma sustancia divina y tras inimaginables intervalos de tiempo vuelven a hundirse de nuevo en su seno. De hecho podemos ver en esta idea una especie de teogonía filosófica". (Jaeger 1992, p. 37).

Si Anaximandro afirmó que el arjé era 'lo indeterminado' deducimos que fue un concepto neutro; carece de género. El carácter de neutralidad significa que contiene en sí la posibilidad de engendrar elementos contrarios y diversos (la oposición), por esta razón se habla simbólicamente de la androginia de lo originario. En el mito hesiódico, por ejemplo, el Caos puede tener esta significación andrógina o neutra, puesto que Hesíodo jamás menciona el género de éste. La neutralidad de género de lo primigenio en la filosofía de Anaximandro se identifica con un principio racional, desantropomorfizado y abstracto.

El próximo paralelismo del caos hesiódico con el ápeiron se basa en la concepción de la Justicia para ambos autores. En La Teogonía se describe el proceso de sublevación de la figura de Zeus a través de la imposición de su justicia en el mundo. El escenario se narra en La Titanomaquia cuando Zeus lucha en contra de los Titanes, los vence y finalmente los sumerge al Tártaro (lugar inframundano relacionado con el caos) para pagar su expiación por cometer injusticia a Urano (narrado en El Mito de la Castración de Urano). Esto es compatible con la idea de Anaximandro de que por injusticia las cosas retornan al estado indeterminado originario. Esto puede considerarse para todos ámbitos que conforman el cosmos, incluso la existencia humana.

En los naturalistas milesios no podemos exentar la especulación acerca de lo humano: todo retorna al estado originario; la mortalidad es tan sólo un límite material que nos reconcilia con la materia originaria. Una vez retornando ésta, permanece en espera de una nueva forma de vida. 
Asumiendo que la existencia es un modo de injusticia cósmica, es necesario tener en cuenta que la formulación cosmológica de Anaximandro no descarta el problema de lo humano, más bien lo difumina con el problema de la Physis. Jean Brun nos dice al respecto de la existencia: "tal visión del mundo se une pues a la de Anaximandro, para quien los entes, al dar nacimiento a la individuación, cometieron el crimen que pagan por su status óntico de individuos; si se hacen justicia y reparación unos a otros de su injusticia según el orden del tiempo, esto se debe a que, gracias a la metempsicosis, tratan de descubrir, en una exploración de la pluralidad de los seres, una compensación el continente que abandonaron". (Brun 1993, p. 17).

En La Teogonía de Hesíodo, el mundo no puede concebirse sin la justicia de Zeus, lo mismo para en la cosmología filosófica de Anaximandro; sin la justicia que retorna al ápeiron el mundo carecería de orden y armonía. En Mesopotamia lo mismo sucede con la intervención de orden cósmico por Marduk.

En Egipto y Mesopotamia vieron el caos primigenio como una amenaza de otras culturas hacia su propia identidad, por lo que siempre interpretaron lo originario como algo negativo y que ponía en peligro la vida de su cosmos. Pero, remitiéndome a la opinión de Vernant, gracias al momento sociopolítico que aconteció en Grecia en el siglo VI a. de C., el origen común del mundo cobra un nuevo sentido: el sentido del ágora como punto de la opinión pública y deliberación de los asuntos de la polis griega.

Podemos ver ahora la continuidad del problema del cosmos en la filosofía respecto del mito hesiódico. Por un lado se intentó resolverlo por explicaciones divinas y poéticas y por otro mediante una vía racional y abstracta prescindiendo de figuras religiosas; aún con esta diferencia fundamental, ambas posturas tienen visibles rasgos en común.

\section{Conclusiones}

Las filosofías cosmogónicas de Tales y Anaximandro que emergieron en Mileto hacia el siglo VI a. d. C., tuvieron una continuidad con el problema que los mitos cosmogónicos comparten: se trata también de comprender el orden del mundo. Pero esta comprensión abstracta y racional que propuso la filoso-

fía en sus primeros momentos no se desembarazó del todo de la especulación 
mágico-religiosa de los mitos. En la cosmogonía filosófica de los milesios siguieron permaneciendo elementos que la instauran en los mismos dominios de lo sagrado, sobre todo en el momento que cada uno de los físicos milesios propuso un elemento unificador del cosmos. Esto quiere decir que el trasfondo en el que se encontraron trazados cada uno de los elementos propuestos como originarios y unificadores, siguió teniendo rasgos divinos.

Para el pensamiento cosmogónico la preocupación sobre el origen y fin del mundo es condición necesaria para su formulación. Situar los orígenes en un estado de indiferenciación material es el hilo conductor de este texto y es el punto de unión entre la relación que establecí entre los mitos de formación del mundo de las antiguas civilizaciones expuestas, los griegos y la cosmogonía milesia.

La cuestión del retorno al estado primigenio cósmico vinculado con el problema de la muerte es un punto que merece estudiarse más a fondo. Esto se relaciona tradicionalmente con los rituales, sobre todo dionisiacos; los carnavales y las bacanales, con su carácter orgiástico, son festividades que tienen como fin la disolución de la individualidad en una totalidad caótica que remonta hacia los orígenes: "En la orgía se tiende a la "confusión de formas". por la inversión del orden social, la coincidencia de contrarios, el desencadenamiento de las pasiones incluso en su aspecto destructivo. Todos estos medios lo son menos de obtener placer que de facilitar la disolución del mundo". (Cirlot 1997, p. 348).

Los mitos cosmogónicos nos llevan hacia una visión unificada del mundo; no sólo son simples narraciones poéticas sobre hechos divinos que condujeron hacia el orden del mundo, sino que también son modelos de acción en el mundo humano. Se trata de conocer el principio y el fin de acuerdo a un orden inquebrantable, una ley que sirve de punto de partida para la conformación del mundo humano.

\section{Referencias}

Aristóteles, 2000, La Metafísica, Gredos, Madrid.

—, 2006, La Física, Bibliotecaurum grecorum et romanorum, UNAM, México.

Böhme, G., 1998, Fuego, agua, tierra, aire: una historia cultural de los elementos, Herder, Madrid.

Bottéro, J., 2001, La religión más antigua: Mesopotamia, Trotta, Madrid. 
Brun, J., 1993, El retorno de Dionisos, A pleno sol, Madrid.

Castoriadis, C., 2006, Lo que hace a Grecia: De Homero a Heráclito, Fondo de Cultura Económica, México.

Cirlot, E., 1997, Diccionario de símbolos, Siruela, Barcelona.

Cohn, N., 1995, El cosmos, el caos y el mundo venidero: las antiguas raíces de la fe apocalíptica, Crítica, Barcelona.

Colli, G., 2002, La sabiduría griega 1, Trotta, Madrid.

Cornford, F. M, 1998, Principium Sapientiae. Los Orígenes del pensamiento filosófico griego, La Balsa de Medusa, Madrid.

Chevalier, J., Gheerbrant, A.,1999, Diccionario de Simbolos, Herder, Barcelona.

Detienne, M., 2001, Los maestros de la verdad en la Grecia arcaica, Sexto piso, Barcelona.

Doods, E.R., 2000, Los griegos y lo irracional, Alianza Editorial, Barcelona.

Eliade, M., 2000, Historia de las creencias y las ideas religiosas: de la edad de piedra a los misterios de Eleusis, volumen 1, Paidós, Barcelona.

—, 1998, Lo sagrado y lo profano, Paidós, Barcelona. , 2007, Tratado de Historia de las religiones, Biblioteca Era, México.

Eurípides, 2000, Tragedias, Gredos, Madrid.

Farrington, B., 1977, Ciencia y Filosofía en la antigüedad, Ariel, Barcelona.

Gigon, O., 1985, Los orígenes de la filosofía griega, Gredos, Madrid.

Gimberg, C., Svanström R., 1967, Grecia, Editorial Daimón coleccción Historia Universal, Barcelona.

Graves, R., 2007, Los mitos griegos, volumen 1, Alianza Editorial, Madrid. 2007, Los mitos griego, volumen 2, Alianza Editorial, Madrid.

Guthrie, W.K.C., 1991, Historia de la filosofía griega, Tomo I, Gredos, Madrid.

Hesíodo, 2000, Teogonía, en Obras y Fragmentos, Gredos, Madrid. , 2000, Los Trabajos y los Días en: Obras y Fragmentos, Gredos, Madrid.

Homero, 2000, La Odisea, Gredos, Madrid.

Hübner, K., 1996, La Verdad del mito, Siglo XXI, México.

Jaeger, W., 1995, Paideia, Fondo de Cultura Económica, México.

—, 1992, La Teología de los primeros filósofos griegos, Fondo de Cultura Económica, México.

Kerényi, C., 1961, The gods of the Greeks, Thames and Hudson, London.

Kirk, G. S, 2002, La naturaleza de los mitos griegos, Paidós, Barcelona.

Kirk, G.S., Raven, J.E., Schofield, M., 1987, Los filósofos presocráticos, Gredos, Madrid.

Los filósofos presocráticos: fragmentos

, Tomo I, 1994, Traducción y notas: Conrad Eggers Lan, et al, Gredos, Madrid.

Martínez Nieto, R., 2000, La aurora del pensamiento griego: Las cosmogonías prefilosóficas de Hesiodo, Alcmán, Ferecides, Epiménides, Museo y La Teogonía órfica antigua, Trotta, Madrid.

Minois, G., 1994, Historia de los Infiernos, Taurus, Barcelona. 
Nietzsche, F., 2001, El nacimiento de la Tragedia, Alianza, Madrid.

Parain, B. (comp.), 1999, Historia de la filosofía: El pensamiento prefilosófico y oriental, Volumen I, Siglo XXI, Madrid.

Sambursky, S, 1990, El mundo físico de los griegos, Alianza, Madrid.

Vernant, J.P., 2001, Mito y pensamiento en la Grecia Antigua, Ariel, Barcelona.

, 1999, Érase una vez (...) El universo, los dioses, los hombres, Fondo de Cultura Económica, Buenos Aires.

, 1986, La muerte en los ojos: figuras del Otro en la antigua Grecia, Gedisa, Barcelona. , 1992, Los Orígenes del pensamiento griego, Paidós, Barcelona.

Recibido el 26 de Mayo de 2011

Aceptado el 12 de Julio de 2011 